\title{
Morphologic Variations in Mandibular Premolars: A Report of Three Cases
}

\author{
${ }^{1}$ Anuj Bhardwaj, ${ }^{2}$ Jojo Kottoor, ${ }^{3}$ Denzil Valerian Albequerque, ${ }^{4}$ Natanasabapathy Velmurugan
}

\section{ABSTRACT}

Aim: To report cases with morphologic variations in mandibular premolars.

Background: Mandibular premolars have earned the reputation for having aberrant anatomy. The occurrence of three canals with three separate (type $\mathrm{V}$, Vertucci) foramina in mandibular premolars is very rare. In this report, three cases are presented involving the root canal treatment of mandibular premolars with three different root and canal configurations. The present report also emphasizes the use of the dental operating microscope to enhance visualization.

Case description: Correlation between radiographic findings, use of dental operating microscope and knowledge of aberrant anatomy helps to identify, locate and treat the aberrant anatomy of the tooth.

Clinical significance: The treatment was successful as all canals were identified and filled and also as evidenced by relief of symptoms.

Conclusion: Success is largely dependent on the use of magnification, which aided in identifying the location of the three individual root canal orifices; thus emphasizing the need to familiarize ourselves with dental microscopy, to obtain maximal anatomic information in endodontic practice.

Keywords: Mandibular first premolar, Mandibular second premolar, Root canal anatomy, Tooth morphology.

How to cite this article: Bhardwaj A, Kottoor J, Albequerque DV, Velmurugan N. Morphologic Variations in Mandibular Premolars: A Report of Three Cases. J Contemp Dent Pract 2014;15(5): 646-650

\footnotetext{
${ }^{1-3}$ Senior Lecturer, ${ }^{4}$ Professor and Head

${ }^{1}$ Department of Conservative Dentistry and Endodontics Modern Dental College and Research Centre, Indore, Madhya Pradesh, India

${ }^{2}$ Department of Conservative Dentistry and Endodontics, Mar Baselios Dental College, Kothamangalam, Kerala, India

${ }^{3}$ Department of Conservative Dentistry and Endodontics, Terna Dental College, Navi Mumbai, Maharashtra, India

${ }^{4}$ Department of Conservative Dentistry and Endodontics Meenakshi Ammal Dental College, Chennai, Tamil Nadu, India

Corresponding Author: Anuj Bhardwaj, Senior Lecturer Department of Conservative Dentistry and Endodontics Modern Dental College and Research Centre, Indore, Madhya Pradesh, India, e-mail: dranuj_84@yahoo.co.in
}

\section{Source of support: Nil}

\section{Conflict of interest: None}

\section{BACKGROUND}

Teeth that present variations in their pulp space anatomy are candidates for unsuccessful treatment outcome, if an accurate diagnosis and management are not performed. Anatomical variation is prevalent in many teeth, with some teeth having as many as five separate roots ${ }^{1}$ and even seven ${ }^{2}$ or eight ${ }^{3}$ separate root canals to clean and shape. However, mandibular premolars may present with the greatest difficulty of all teeth to be treated endodontically and have the highest failure rate of nonsurgical root canal treatment. ${ }^{4,5}$ The possible reasons for a high failure rate in these teeth are the numerous variations in root canal morphology added to the difficulty in access to the additional canal/s. ${ }^{5}$ The present article describes three cases of mandibular premolars, each presenting with three root canals, but different root and canal configurations. Additionally a review of the related literature provides an analysis for achieving endodontic success in similar cases.

\section{CASE REPORTS}

These are the case reports of three patients treated in the Department of Conservative Dentistry and Endodontics, Meenakshi Ammal Dental College, Chennai, India. A thorough history was recorded, and the cases were examined both clinically and radiographically. The medical history of all patients was noncontributory. Vitality testing of the involved tooth was carried out with heated gutta-percha (Dentsply Maillefer, Ballaigues, Switzerland), cold test (RC Ice, Prime Dental Products Pvt. Ltd., Mumbai, India) and electronic pulp stimulation (Parkel Electronics Division, Farmingdale, NY). Local anesthesia was obtained with $2 \%$ lignocaine containing 1:200,000 epinephrine (Xylocaine, AstraZeneca Pharma Ind Ltd, Bengaluru, India). The entire procedure in each case was carried out using rubber dam isolation under a dental operating microscope (DOM) (Seiler Revelation Microscope, St. Louis, MO). The working length was determined with an apex locator (Root ZX; Morita, Tokyo, Japan) and confirmed radiographically. Cleaning and shaping were performed using a crown-down technique with ProTaper series NiTi rotary instruments (Dentsply Maillefer, Ballaigues, Switzerland) 
with irrigation using normal saline, $3 \%$ sodium hypochlorite and $17 \%$ ethylenediaminetetraacetic acid (EDTA). When preparation was complete, the irrigants were agitated using endosonics (Piezon master, Optident, Skipton, UK). All canals were dried with absorbent points and obturated using gutta-percha and AH Plus sealer (Dentsply Tulsa). Patients were referred for further restorative needs and were found to be asymptomatic during the subsequent follow-up period.

\section{Case 1}

A 27-year-old male patient presented with a chief complaint of 'sharp pain in his left lower back tooth'. Clinical examination showed proximal caries in the mandibular left second premolar (tooth \#35), which was accompanied by tenderness to percussion. The preoperative diagnostic radiograph revealed a disto-occlusal radiolucency approaching the pulpal outline with at least two separate roots and canals (Fig. 1A). A diagnosis of symptomatic irreversible pulpits with symptomatic apical periodontitis was made for tooth \#35 and root canal treatment was scheduled. Initial observation of the pulp chamber floor revealed two root canal orifices, distal and mesiobuccal. Further inspection under a DOM and exploration with DG-16 endodontic explorer (Hu-Friedy Chicago, IL, USA), revealed the presence of an additional canal mesiolingually (Fig. 1B). The working length was determined (Fig. 1C), canals instrumented, medicated with calcium hydroxide and the tooth temporized using intermediate restorative material (IRM). At the next visit a week later, canals were cleaned, dried and obturated, followed by a composite core restoration (Fig. 1D).

\section{Case 2}

A 32-year-old female patient reported with the chief complaint of sharp, continuous pain in the lower left region. Clinical examination revealed a carious left mandibular first premolar (tooth \#34) that was tender to percussion. Radiographically the mandibular left first premolar showed a complex root canal system with at least two roots and canals (Figs 2A to D). A diagnosis of necrotic pulp with symptomatic apical periodontitis was made necessitating endodontic treatment. Root canal treatment was scheduled over two visits due to the complexity of the root canal system. On
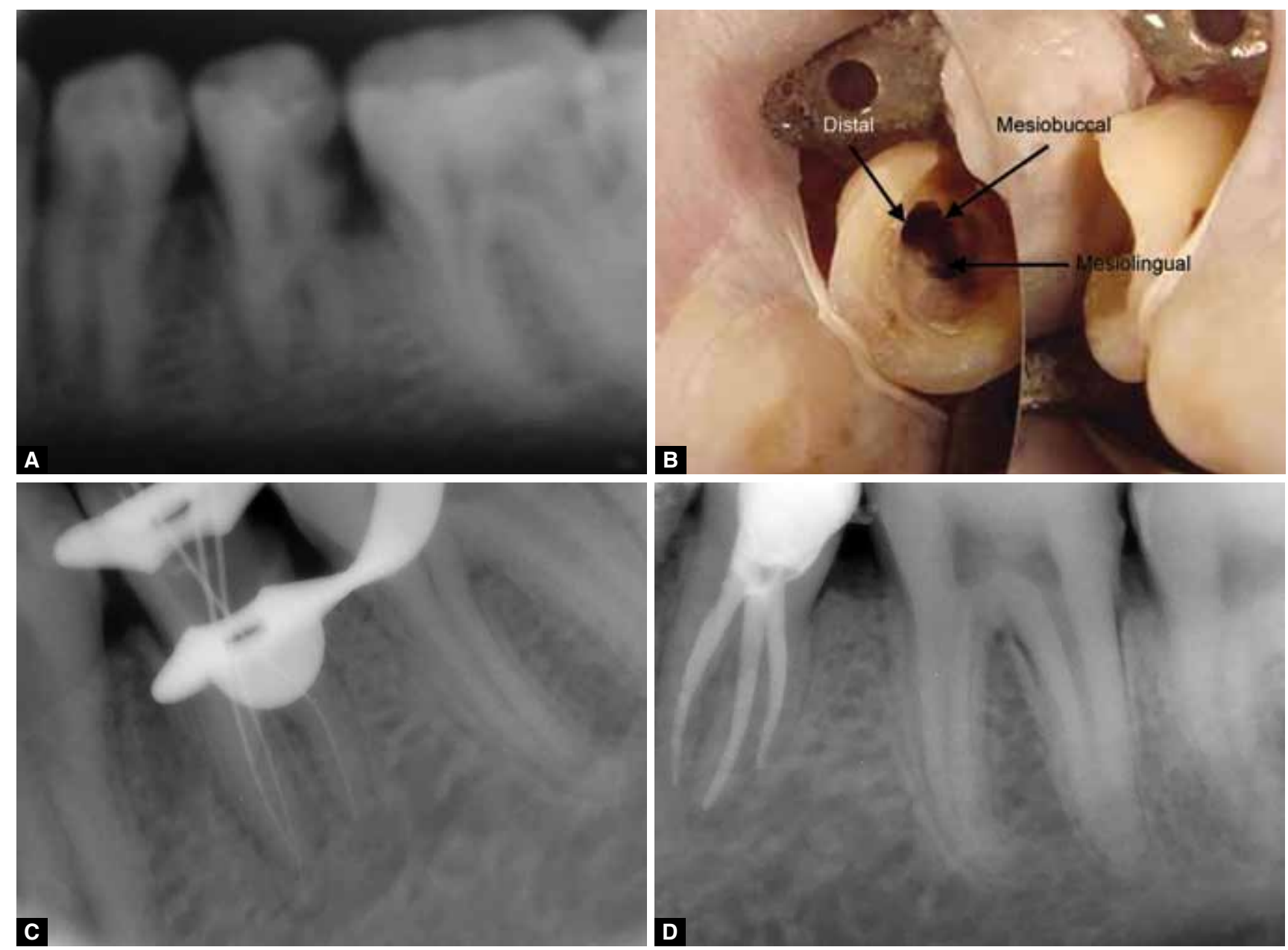

Figs 1A to D: (A) Preoperative radiograph of the tooth \#35 with mid-root bifurcation into two roots, (B) access reveals three root canal orifices, $(C)$ working length radiograph demonstrates three root canals and (D) mesially angulated postoperative radiograph showing three separate root and canals 

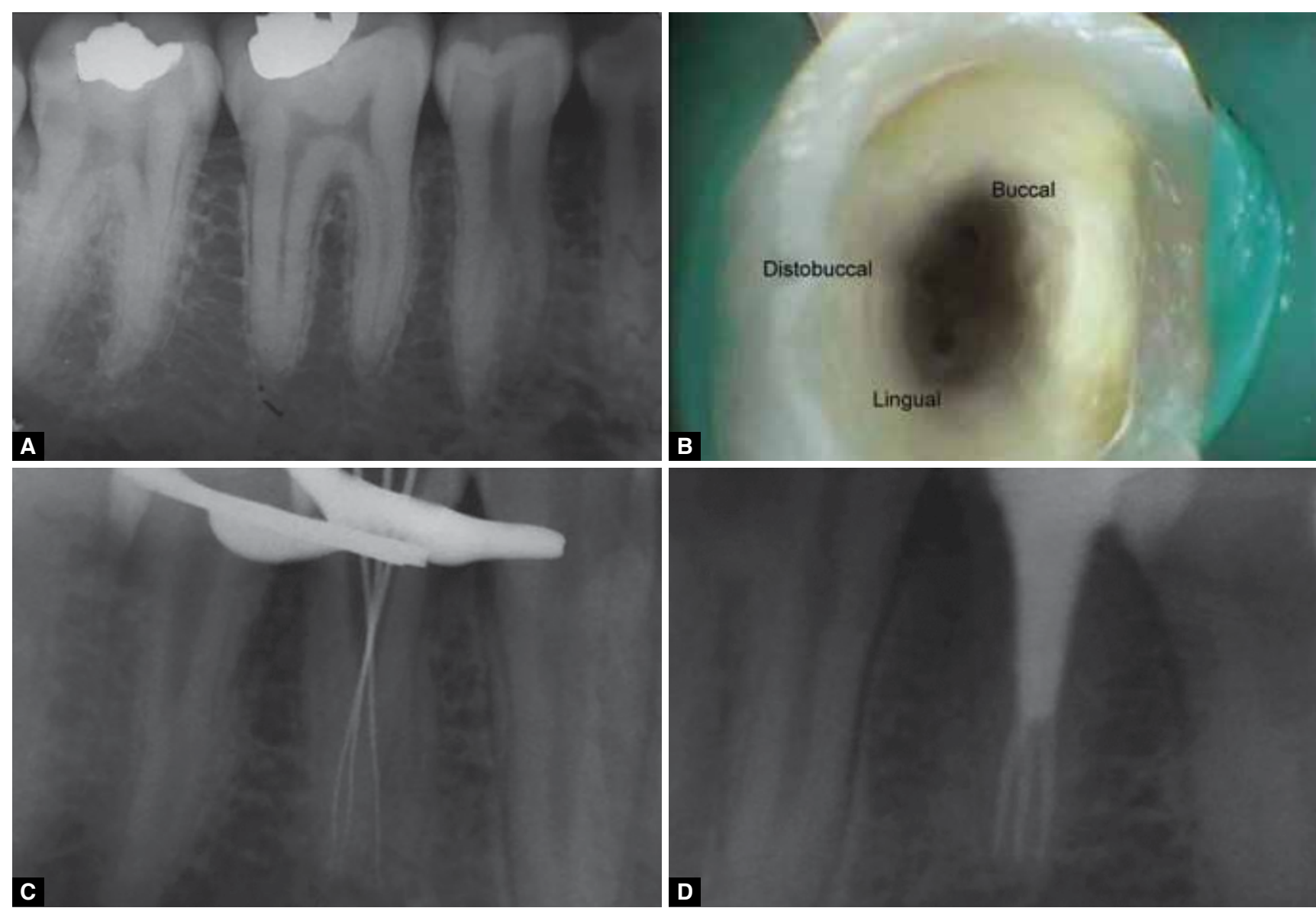

Figs 2A to D: (A) Preoperative radiograph of tooth \#34, (B) access reveals one main canal with a trifurcation at the mid-root level, (C) working length radiograph demonstrated three root canals and (D) postoperative radiograph

achieving endodontic access, a canal was identified in each of the two roots in a buccolingual direction, using size 08 $\mathrm{K}$-file. However, further microscopic examination identified a third orifice distobuccally, which was confirmed radiographically as a second canal in the buccal root. Coronal flaring was carried out with ProTaper Sx (Fig. 2B) and the working length was confirmed with a radiograph (Fig. 2C). After chemomechanical preparation, all canals were dried with paper points and a calcium hydroxide dressing placed. One week later, the root canal system was obturated (Fig. 2D). The access cavity was restored with miracle mix.

\section{Case 3}

A 20-year-old male was referred for endodontic treatment of the lower left first premolar. The patient presented with a history of an alleged road traffic accident about a month back, which was diagnosed as a parasymphysial fracture of the left mandible and surgical reduction had been performed using metallic plates. Clinically, the tooth was structurally intact and mobility was within physiological limits, but was tender to percussion. The tooth responded negatively to vitality testing. Radiographically, the lower left first premolar showed periradicular periodontal liga- ment widening possibly caused by the proximity of the radiolucent fracture line to the tooth. A diagnosis of necrotic pulp with symptomatic apical periodontitis was made necessitating endodontic treatment. Multiple angulated preoperative radiographs revealed the possibility of a middle third canal bifurcation (Figs 3A and B). The endodontic access cavity initially presented with a buccal and a lingual canal, however on further exploration using magnification, a third canal was located distally and the canal morphology was confirmed radiographically (Fig. 3C). After biomechanical preparation, all canals were dried with paper points and medicated with calcium hydroxide. A week later, the root canal system was obturated and the access cavity was sealed with silver amalgam (Fig. 3D).

\section{DISCUSSION}

In most instances, mandibular premolars have one root and a single root canal. ${ }^{6-10}$ However, anatomical variations of mandibular premolars are well documented in the literature. More commonly encountered variations include teeth with two roots and/or canals ${ }^{11,12}$ whilst other rare aberrations like three, ${ }^{13}$ four ${ }^{14}$ and five ${ }^{15}$ root canals have been documented. However, the occurrence of three canals with three separate 

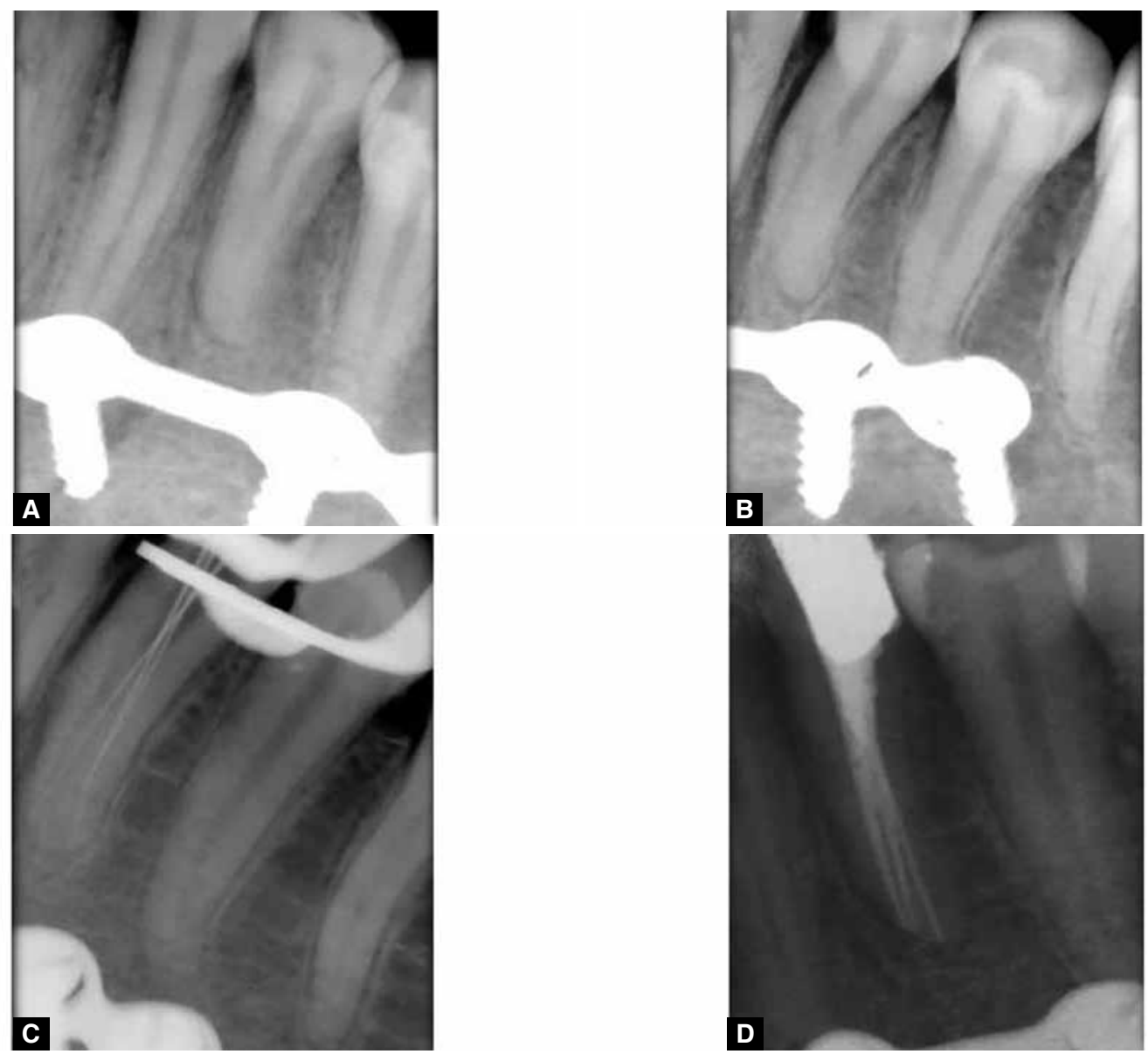

Figs $3 A$ to $D$ : $(A$ and $B)$ Multiple angulated preoperative radiographs of tooth $\# 34,(C)$ working length radiograph reveals one main canal with a trifurcation at the mid-root level and (D) postoperative radiograph

foraminal exits (Vertucci Type V) is very rare. Vertucci ${ }^{10}$ and Zillich and Dowson ${ }^{8}$ reported the occurrence of three canals in mandibular first premolars at 0.5 and $0.4 \%, 0.0$ and $0.4 \%$ in second premolars, respectively.

All three cases of mandibular premolars discussed here demonstrated variable patterns of foraminal exits. In the first case, the root system was characterized by a complete mid-root separation of the three roots with its corresponding canals. In the second case, there were two roots and three canals, but all the identified canals had a separate orifice and exiting foramen. However, in the third case, all the three root canals were within a single root, but had independent foraminal exits. These complexities and variations in mandibular premolars with regards to the roots, apical third anatomy and foraminal exits play a significant role in determining longterm endodontic success. Additionally, such variability of the root canal system also needs due consideration during endodontic surgery.

Mandibular premolars are an endodontic challenge, especially when it presents with variable anatomy. ${ }^{4}$ An increase in the number of canals adds to the difficulty because of the canal axis angle. Also, the coronal tooth structure needs to be preserved and the endodontic access must not be widened too much to avoid complications restorative complications. Additionally, any bifurcation or trifurcation that may be encountered deeper into the root further complicates visibility and access.

Several clinical indicators may be useful in the detection of a third and fourth canal in mandibular second premolars. For example, third and fourth canals could be suspected clinically when the pulp chamber does not appear to be aligned in its classic buccolingual relationship. Also, if the pulp chamber appears to deviate from its normal configuration and appears to be either triangular in shape or wider in a mesiodistal plane, more than one canal should be suspected. Additionally, tactile exploration of all the walls of the major canal(s) with a precurved \#08 or \#10 ISO K-file is recommended, in order to probe for a catch, which may indicate the presence of an additional canal.

\section{CLINICAL SIGNIFICANCE}

The present cases describe the successful completion of nonsurgical endodontic treatment of mandibular premolars containing three different root canal systems. The cases also contribute to our knowledge of the root canal systems and the anatomy of mandibular premolars. Success was 
largely dependent on the use of magnification, which aided in identifying the location of the three individual root canal orifices; thus emphasizing the need to familiarize ourselves with dental microscopy, to obtain maximal anatomic information in endodontic practice.

\section{REFERENCES}

1. Kottoor J, Hemamalathi S, Sudha R, Velmurugan N. Maxillary second molar with 5 roots and 5 canals evaluated using cone beam computerized tomography: a case report. Oral Surg Oral Med Oral Pathol Oral Radiol Endod 2010 Feb;109(2):e162-165.

2. Kottoor J, Velmurugan N, Sudha R, Hemamalathi S. Maxillary first molar with seven root canals diagnosed with cone-beam computed tomography scanning: a case report. J Endod 2010 May;36(5):915-921.

3. Kottoor J, Velmurugan N, Surendran S. Endodontic management of a maxillary first molar with eight root canal systems evaluated using cone-beam computed tomography scanning: a case report. J Endod 2011 May;37(5):715-719.

4. Slowey RR. Root canal anatomy. Road map to successful endodontics. Dent Clin North Am 1979 Oct;23(4):555-573.

5. Ingle J, Bakland L. Endodontics. 5th ed. Hamilton: BC Decker; 2002.
6. Mueller AH. Anatomy of the root canals of the incisors, cuspids and bicuspids of the permanent teeth. J Am Dent Assoc 1933; 20:1361-1386.

7. Pineda F, Kuttler Y. Mesiodistal and buccolingual roentgenographic investigation of 7275 root canals. Oral Surg Oral Med Oral Pathol 1972 Jan;33(1):101-110.

8. Zillich R, Dowson J. Root canal morphology of mandibular first and second premolars. Oral Surg Oral Med Oral Pathol 1973 Nov; 36(5):738-744.

9. Kerekes K, Tronstad L. Morphometric observations on root canals of human premolars. J Endod 1977 Feb;3(2):74-79.

10. Vertucci FJ. Root morphology of mandibular premolars. J Am Dent Assoc 1978 Jul;97(1):47-50.

11. Green D. Double canals in single roots. Oral Surg Oral Med Oral Pathol 1973 May;35(5):689-696.

12. Shapira Y, Delivanis P. Multiple-rooted mandibular second premolars. J Endod 1982 May;8(5):231-232.

13. Poorni S, Karumaran CS, Indira R. Mandibular first premolar with two roots and three canals. Aust Endod J 2010 Apr;36(1):32-34.

14. Holtzman L. Root canal treatment of mandibular second premolar with four root canals: a case report. Int Endod J 1998 Sep;31(5):364-366.

15. Macri E, Zmener O. Five canals in a mandibular second premolar. J Endod 2000 May;26(5):304-305. 